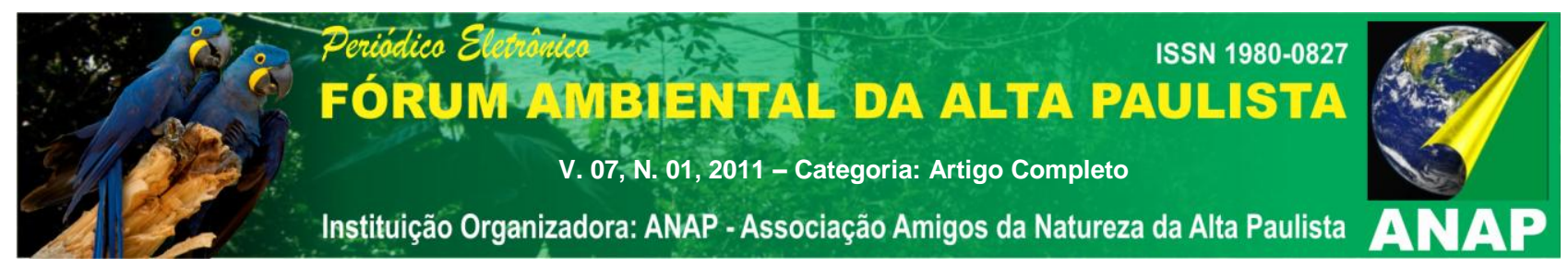

\title{
REFLEXÕES SOBRE AS CARACTERÍSTICAS REGIONAIS E ESTADUAIS NO MERCADO DE ETANOL HIDRATADO BRASILEIRO ENTRE 2000 E 2009.
}

\author{
Sérgio Rangel Fernandes Figueira ${ }^{1}$
}

RESUMO: Realizou-se uma pesquisa sobre a demanda por etanol hidratado no Brasil comparativamente a demanda por gasolina C e gás natural veicular (GNV), principais concorrentes do etanol hidratado em veículos automotivos, e sobre as tendências de demanda e os preços relativos da gasolina e do etanol (ambos responderam por $96 \%$ da demanda nacional) nas cinco regiões brasileiras e nos estados com maior participação na demanda de sua região. $O$ período analisado foi de 2000 até 2009. Constatou-se elevação de aproximadamente $53,8 \%$ na demanda por combustíveis no país. A gasolina é o combustível mais demandado, representando $58 \%$ da demanda em 2009, participação menor do que a de $82 \%$ obtida em 2000 . A demanda por etanol se elevou em $257 \%$ no período analisado. Ao se realizar uma análise das cinco regiões e dos maiores estados demandantes nas regiões, observa-se que grande parte da elevação da demanda nacional ocorreram em estados produtores de etanol e/ou com menores Impostos de Circulação de Mercadorias e Serviços (ICMS) para o etanol hidratado em relação ao adotado para a gasolina.

Palavras chave: etanol, demanda e estados.

\footnotetext{
${ }^{1}$ Professor Assistente Doutor na Faculdade de Ciências Agrárias e Veterinárias da UNESP de Jaboticabal E-Mail: figueira@fcav.unesp.br).
} 
INTRODUÇÃO

$\mathrm{Na}$ década de 1990, intensifica-se o debate no cenário internacional sobre a necessidade de redução das emissões de gases causadores do efeito estufa. Em 1992, ocorreu a conferência ECO-92 no Rio de Janeiro. O seu objetivo principal era buscar meios de conciliar o desenvolvimento sócio-econômico com a conservação e proteção dosecossistemas da Terra. As Mudanças Climáticas resultantes do efeito estufa e a necessidade de mitigar a emissão de gases causadores do efeito estufa foi um dos eixos temáticos da conferência.Em 1997, em Quioto, foi elaborado um protocolo de um tratado internacional com compromissos mais rígidos para a redução da emissão dos gases que agravam o efeito estufa, considerados, de acordo com a maioria das investigações científicas, como causa antropogênicas do aquecimento global.

As elevadas e crescentes emissões de dióxido de carbono $\left(\mathrm{CO}_{2}\right)^{2}$, principais responsáveis pelo efeito estufa, são geradas pelo modelo de produção e de consumo energético, que se baseia no uso intensivo dos recursos fósseis não renováveis: carvão mineral, petróleo e gás natural Além do modelo energético, a destruição de florestas e ecossistemas também vem contribuindo para o efeito estufa.

Devido a necessidade de redução da emissão dos gases causadores do efeito estufa, exigência do Protocolo de Quioto, e a estratégia dos países em diversificar sua matriz energética, tornando-a menos dependente do petróleo, muitos países, desenvolvidos e em desenvolvimento, estão analisar a possibilidade de implementação de fontes alternativas de energia, como programas de biocombustíveis, energia eólica (energia proveniente dos ventos), a energia fotovoltaíca (energia obtida através da conversão direta da luz do sol em eletricidade).

Estudos realizados apontaram o etanol produzido no Brasil como uma das possíveis alternativas para substituir os derivados de Petróleo, principalmente a gasolina

\footnotetext{
${ }^{2} \mathrm{O}$ dióxido de carbono $\left(\mathrm{CO}_{2}\right)$ não é um gás tóxico, não sendo considerado, portanto, um poluente atmosférico local. Embora não tóxico, $\mathrm{o} \mathrm{CO}_{2}$ é um dos principais gases responsáveis pelo efeito estufa; desta forma, considera-se o $\mathrm{CO}_{2}$ como um poluente global.
} 
nos combustíveis automotivos, e propiciar uma redução na emissão de dióxido de carbono. A partir desta análise, o setor público brasileiro e o setor privado se empenharam em procurar estimular a demanda por etanol no mercado doméstico e em mercados internacionais.

O Governo Federal divulgou em 2006 e 2008 dois planos para estimular a utilização de etanol brasileiro no mercado doméstico e internacional. Em 2006, o governo federal divulgou o Plano Nacional de Agroenergia no período de 2006-2011. Em 2008, o governo divulgou o Plano Nacional de Mudanças Climáticas. Em ambos, os biocombustíveis, principalmente o etanol, assumem destacada relevância na matriz energética brasileira dos próximos anos e na estratégia brasileira de combate ao efeito estufa, candidatando-se a ser um grande exportador de agroenergia.

Postas as estratégias do governo federal brasileiro em utilizar o etanol nacional como forma de reduzir a emissão de gases geradores do efeito estufa e estimular sua utilização no mercado nacional e internacional, faz-se a seguir um breve relato das características do mercado de etanol hidratado brasileiro.

Como a produção de petróleo não acompanhou a elevação da demanda pela gasolina e outros derivados de petróleo até a década de 1970, o país atravessou problemas no seu Balanço de Pagamentos devido a elevação dos preços do petróleo no mercado mundial. Para equacionar este problema o governo federal buscou alternativas para reduzir a necessidade de utilização de derivados de petróleo e conseqüente necessidade de importação do produto. Surge desta necessidade, em 1975, o Programa Nacional do Álcool (PROALCOOL) com o intuito de incentivar a produção e demanda de álcool combustível em detrimento da utilização de gasolina. O Brasil foi pioneiro na utilização do álcool como combustível em larga escala. O objetivo do programa brasileiro foi o de estimular uma fonte doméstica de produção de energia em substituição ao petróleo importado, que passava por um processo de encarecimento no período.

Após o declínio do Programa Brasileiro de Álcool combustível entre 1989 e 2002, a demanda voltou a ser estimulada, a partir de 2003, pelo grande incremento na venda de 


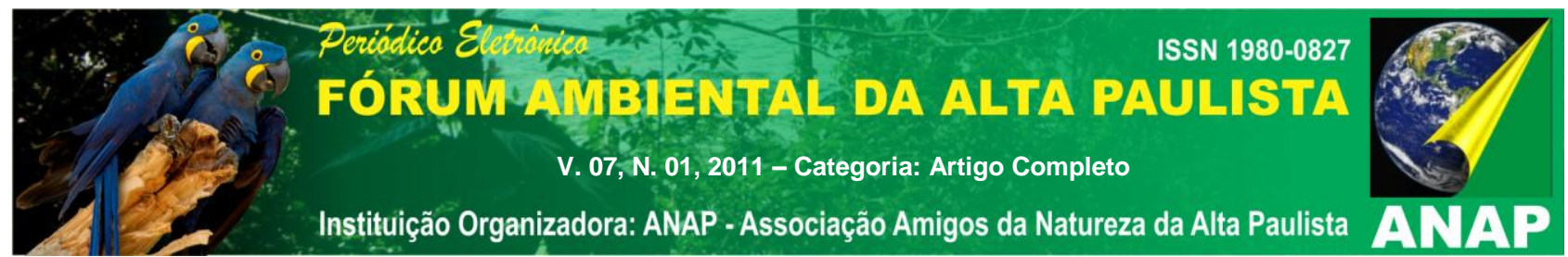

carros bicombustíveis no mercado interno e pela manutenção da competitividade do preço do álcool em relação ao preço da gasolina para veículos automotores.

Postos os compromissos nacionais para se estimular a demanda por etanol hidratado no mercado interno e internacional e as características deste mercado. Necessita-se a realização de pesquisas científicas para se analisar o mercado doméstico de etanol hidratado em relação as outras alternativas de combustíveis e subsidiar o setor público e privado sobre o funcionamento deste mercado.

\section{OBJETIVO}

O objetivo desse artigo é o de realizar uma pesquisa exploratória e comparativa sobre a demanda do etanol hidratado em relação a gasolina, seu principal concorrente, nas principais regiões brasileiras produtoras de demandantes de etanol (Sudeste, Sul, Nordeste e Centro-Oeste) e nos estados com maior nível de participação na demanda de cada região entre 2000 e 2009, período que abrange a introdução dos veículos bicombustíveis.

Para cumprir o objetivo geral, alguns objetivos específicos devem ser cumpridos, tais como:

- Evolução da demanda por etanol, gasolina C e GNV no Brasil.

- Quais regiões e estados mais contribuíram para a demanda nacional por gasolina C e etanol, que respondem majoritariamente pelo consumo de combustíveis automotivos no Brasil.

\section{JUSTIFICATIVA}

Está em curso no Brasil um crescimento da utilização de fontes agroenergéticas, como o etanol e o biodiesel, e postula-se um crescimento destas fontes na matriz energética brasileira e incremento das exportações, principalmente o etanol, como forma de reduzir as emissões de gases geradores do efeito estufa e possibilitar a geração de emprego e renda para o país. Por outro lado, as descobertas de novas reservas de 


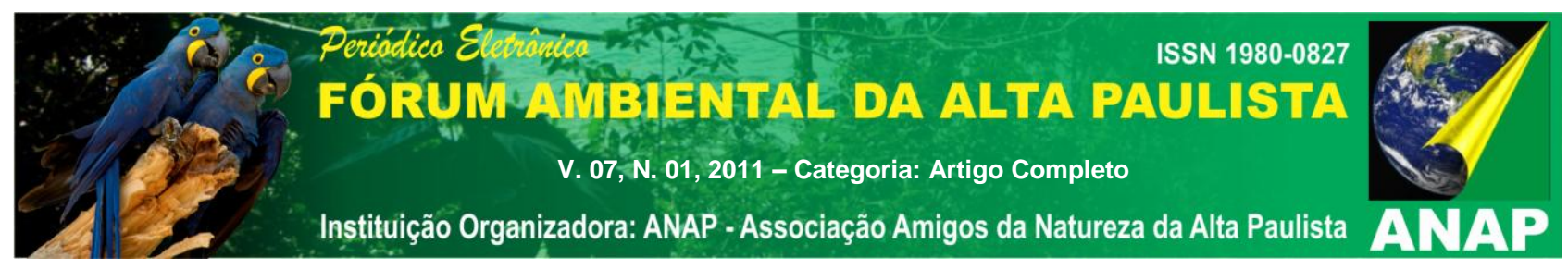

petróleo e gás natural no Brasil e a construção de novas refinarias permitem a ampliação da capacidade de oferta de gasolina e gás natural no Brasil.

Necessitando-se da realização de pesquisas científicas para subsidiar o processo de decisão dos setores público e privado sobre as características da demanda de combustíveis automotivos e das vantagens e desvantagens econômicas, sociais e ambientais de cada alternativa energética para veículos motorizados, como a gasolina, o etanol e o GNV.

\section{METODOLOGIA}

Pretende-se realizar uma pesquisa exploratória e comparativa sobre os combustíveis utilizados para veículos automotivos no Brasil e realizar uma análise comparativa entre as diferentes alternativas de combustíveis para automóveis no Brasil. Para a realização da análise exploratória e comparativa entre a demanda por combustíveis automotivos no Brasil, a pesquisa utilizou como fonte de dados o Anuário Estatístico Brasileiro do Petróleo, Gás Natural e Biocombustíveis de 2010 para levantar as seguintes informações relativas ao período de 2000 e 2009:

- Evolução anual da quantidade demanda de gasolina C, etanol e GNV no Brasil.

- Evolução anual da quantidade demandada de gasolina $C$ e etanol nas cinco regiões brasileiras e nos estados com maior participação na demanda de cada região

- Análise das características do mercado de combustíveis automotivos brasileiro, avaliando os estados que mais contribuem para a demanda de combustíveis e as características regionais e estaduais da demanda por combustível automotivo.

\section{REVISÃO BIBLIOGRÁFICA}




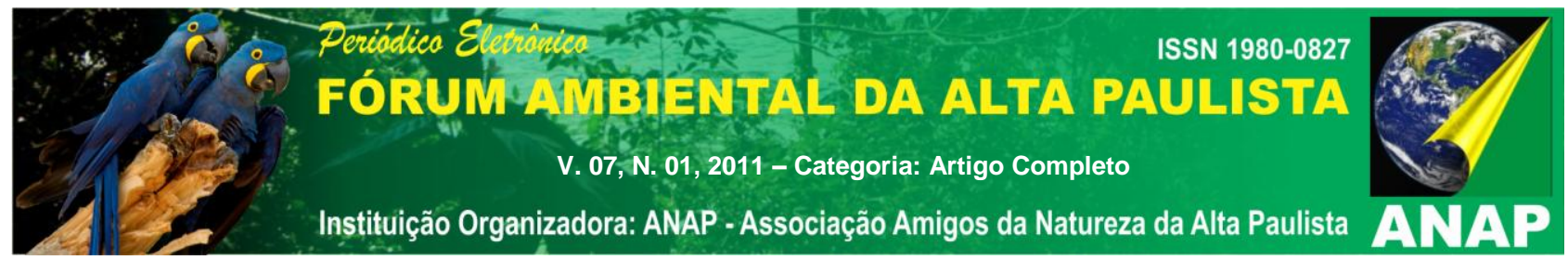

A revisão bibliográfica se ocupará em realizar um breve histórico sobre o mercado de etanol hidratado no Brasil. Trazendo também algumas estatísticas relativas à produção destes combustíveis e alguns fatos marcantes para se compreender a evolução da demanda destas alternativas de combustíveis no país.

\section{A evolução do programa de etanol brasileiro}

No ano de 1973, os países da OPEP ${ }^{3}$ (Organização dos Países Exportadores de Petróleo), atuando na forma de cartel, entraram em acordo para reduzir a produção de petróleo mundial, de forma coordenada, ou seja, determinando-se níveis de produção para cada um dos países membros. Isso desencadeou o primeiro choque do petróleo. A redução da produção provocou elevação dos preços do petróleo no mercado internacional, afetando todos os países importadores do produto. A tendência de alta nos preços no mercado internacional de petróleo perdurou por toda a década de 1970 (Figueira, 2005).

Nesse período, como o Brasil importava mais de $80 \%$ do petróleo que consumia, as despesas com as importações do país aumentaram de US\$ 6,2 bilhões, em 1973, para US $\$ 12,6$ bilhões, em 1974. O saldo da Balança Comercial passou de um leve superávit de US\$ 7 milhões em 1973, para um déficit de US\$ 4,7 bilhões em 1974. O crescimento do déficit da Balança Comercial desencadeou elevação do déficit da Conta Corrente, passando de US\$ 1,7 bilhão para US\$ 7,1 bilhões (BAER, 1996 apud FIGUEIRA, 2005).

No ano de 1975, anunciou-se a elaboração do Programa Nacional do Álcool, com o intuito de reduzir a necessidade de importação de petróleo, concedendo-se estímulos financeiros à expansão da lavoura canavieira e à montagem de destilarias anexas e autônomas (MORAES, 1999 apud FIGUEIRA, 2005).

Em relação ao processo de implantação do programa, devem ser destacadas duas fases: a primeira abrange o período de novembro de 1975 até 1978, correspondendo ao

\footnotetext{
${ }^{3}$ A formação original da OPEP ocorreu em 1960, incluía Irã, Iraque, Kuwait, Arábia Saudita e Venezuela. Em 1973, oito outros países tinham se unido: Qatar, Indonésia, Líbia, os Emirados Árabes Unidos, Argélia, Nigéria, Equador e Gabão. Em 1973, três quartos das reservas mundiais de petróleo encontravam-se nos territórios da OPEP (MANKIW, 1999).
} 


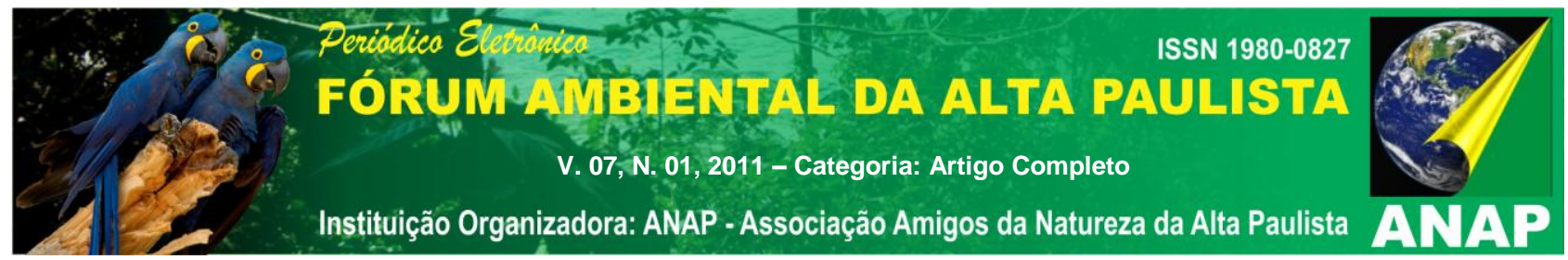

uso da mistura álcool-gasolina, à implantação das destilarias anexas, e ao envolvimento da indústria automotiva para a produção de carros a álcool. Nesta fase ocorreu uma expansão moderada na produção do álcool.

A segunda fase, iniciada em 1979, é a da produção em larga escala do álcool hidratado, para ser usado em carros movidos exclusivamente com este combustível. Diante de um novo conflito no Oriente Médio - entre Irã e Iraque - contribuindo para que os preços do petróleo atingissem patamares elevados, acelerou-se a implementação do uso do álcool hidratado como combustível único (Figueira, 2005).

$\mathrm{Na}$ década de 1990, o declínio dos preços internacionais do petróleo e o fim dos incentivos fiscais para a compra de carros a álcool desestimularam a venda de álcool hidratado neste período. O fim dos incentivos fiscais para a produção de carro a álcool e a crise de abastecimento de $1989^{4}$ são apontados como os principais responsáveis pela reversão na preferência do consumidor em adquirir carro a álcool em detrimento do carro a gasolina. Na década de 1990 e início da década de 2000 tornou-se praticamente irrelevante a venda de carros a álcool em comparação com a de carros a gasolina.

No entanto, o advento dos carros bicombustíveis em 2003 e seu vertiginoso incremento de vendas propiciou novo fôlego para a venda de álcool hidratado, também conhecido como etanol. Como reflexo do incremento da venda de carros bicombustíves, no ano de 2009, vendeu-se majoritariamente veículos bicombustíveis, ocorrendo vendas marginais de veículos movidos a gasolina.

Com a aquisição de carros bicombustíveis, cabe ao consumidor a escolha entre abastecer o tanque de seu carro com álcool hidratado ou gasolina. Como se gasta mais álcool do que gasolina por quilometro rodado, estima-se que o preço do álcool deva ser

\footnotetext{
${ }^{4} \mathrm{Em} 1989$, assiste-se a greves e boicotes dos canavieiros e fornecedores de cana independentes, à ameaça dos próprios produtores de parar a produção de álcool, a alteração dos vínculos comerciais tradicionais entre fornecedores e usineiros e a denúncia de comercialização clandestina do álcool. Em dezembro, os produtores, alegando compromisso com os usuários de carro a álcool, ameaçam parar de entregar álcool anidro à Petrobrás, "para mais tarde transformá-lo em hidratado". A Petrobrás, alegando grande defasagem nos preços dos derivados, anuncia, entre outras medidas, a diminuição do prazo de faturamento dos derivados enregues às distribuidoras, a drástica redução dos estoques de segurança de álcool e o dramático corte em seus investimentos. Em meados do ano, a empresa adverte aos usuários sobre a possibilidade de faltar álcool. De fato, pouco depois, começa o desabastecimento e as filas se alongam nos postos (SANTOS, 1993apud Figueira, 2005).
} 


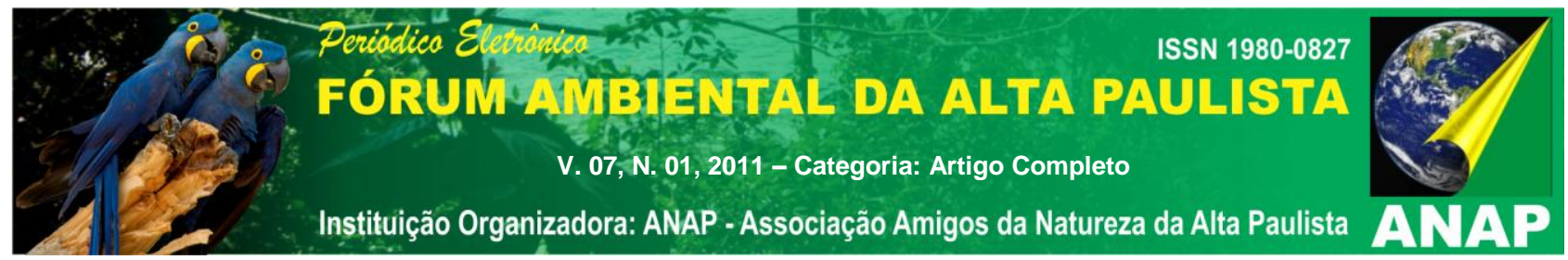

de aproximadamente $70 \%$ do preço da gasolina, para ser indiferente ao consumidor optar por abastecer o veículo com gasolina ou álcool hidratado.

\section{DESENVOLVIMENTO}

Neste tópico, analisa-se a evolução da quantidade demandada de etanol hidratado em comparação aos concorrentes como combustíveis automotivos (gasolina C e GNV) no Brasil entre 2000 e 2009. Desagrega-se também a demanda por gasolina $\mathrm{C}$ e etanol (que respondem majoritariamente pelo mercado de combustíveis nacional), realizando-se uma análise da evolução da quantidade demandada desses combustíveis nas cinco regiões brasileiras e nos estados com maior nível de participação na demanda de combustíveis de cada região. Finaliza-se o tópico discutindo a característica da concentração da demanda por etanol nos estados produtores.

\section{CONSUMO DE COMBUSTÍVEIS NO BRASIL ENTRE 2000 E 2009}

A elevação do consumo de automóveis, principalmente bicombustíveis, desencadeou crescimento da demanda por combustíveis automotivos na década de 2000. Ocorreu elevação de aproximadamente $53,8 \%$ no consumo de combustível para automóvel - considerando a gasolina C, o etanol e o GNV - entre 2000 e 2009. A partir de 2003, o crescimento da demanda por combustível mostrou-se mais elevado.

Entre 2000 e 2009, a gasolina C, misturada com álcool anidro, continuou sendo a alternativa de combustível mais utilizada para veículos automotivos, ver figura 1 . No entanto, a demanda por etanol vem ganhando força e ocupando participação da gasolina no consumo de combustível. O consumo de gasolina reduziu participação no mercado de combustíveis no período analisado, passando de aproximadamente $82 \%$, em 2000 para $58 \%$, em 2009. O etanol elevou participação de mercado, passando de aproximadamente 17\% em 2000 para 38\% em 2009. Entre 2000 e 2009, a demanda por gasolina C sofreu incremento de $12 \%$ ao passo que a demanda por etanol sofreu elevação de aproximadamente $257 \%$. 


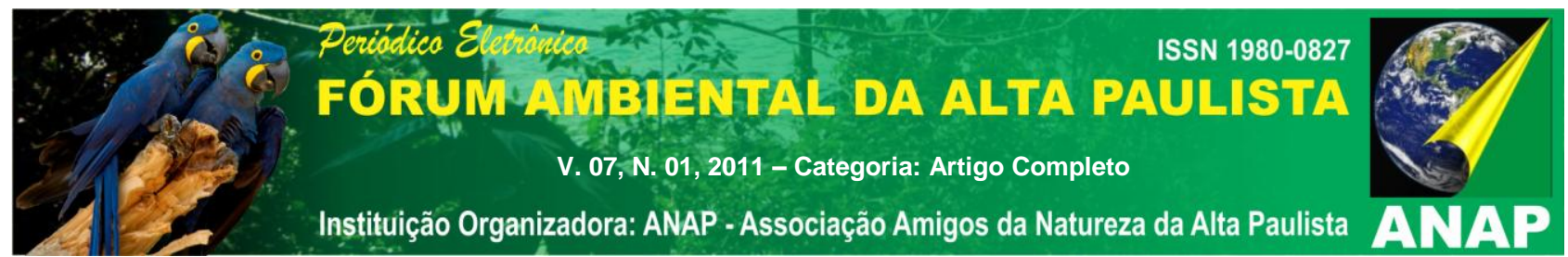

O gás natural veicular sofreu crescimento até 2007, após o ano de 2008 vem ocorrendo decréscimo da utilização desta alternativa de combustível para automóveis. No ano de 2009, o GNV teve participação secundária no mercado de combustíveis, representando aproximadamente $4 \%$ do mercado de combustíveis automotivos.

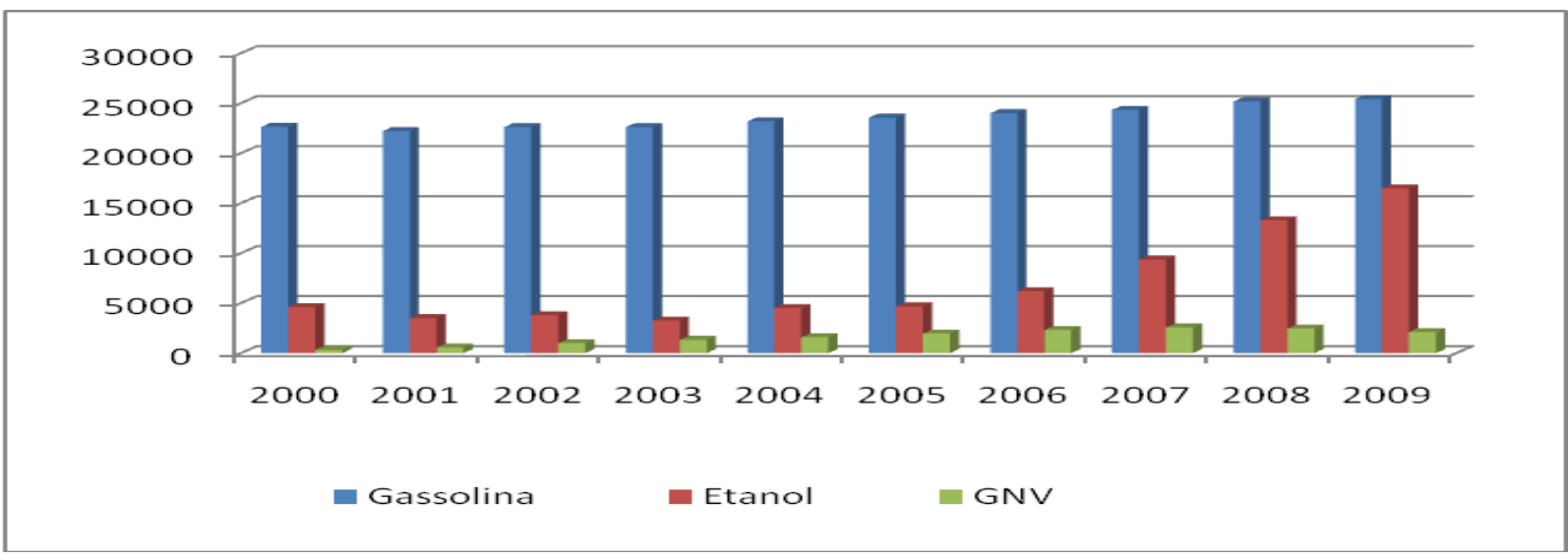

Figura 1: Demanda por gasolina, etanol e GNV, entre 2000 e 2009. Unidade de medida: mil $\mathrm{M}^{3}$.

Fonte: ANP (2010) e EPE (2010).

\section{ANÁLISE REGIONAL DA DEMANDA POR GASOLINA E ETANOL}

Para melhor avaliar a evolução do mercado nacional de etanol e gasolina $C$ entre 2000 e 2009, majoritários no consumo de combustível automotivo no cenário nacional, faz-se uma análise regional. A região Sudeste responde pelo maior nível de consumo destes dois tipos de combustível no país, ver figura 2. No ano de 2000, a participação da região era de $54,6 \%$ no consumo de combustível nacional e em 2009 , a participação caiu ligeiramente para 54,2\%. Em segundo lugar, a região Sul apresentou uma participação de $17,6 \%$ no mercado nacional de combustíveis em 2009, ocorrendo perda de participação, pois detinha 19,8\% em 2000. A região Nordeste vem em terceiro e apresentou ligeira elevação na participação no mercado, passando de $13 \%$ para $13,5 \%$. A região CentroOeste, quarta colocada, também passou por um processo de elevação na participação 


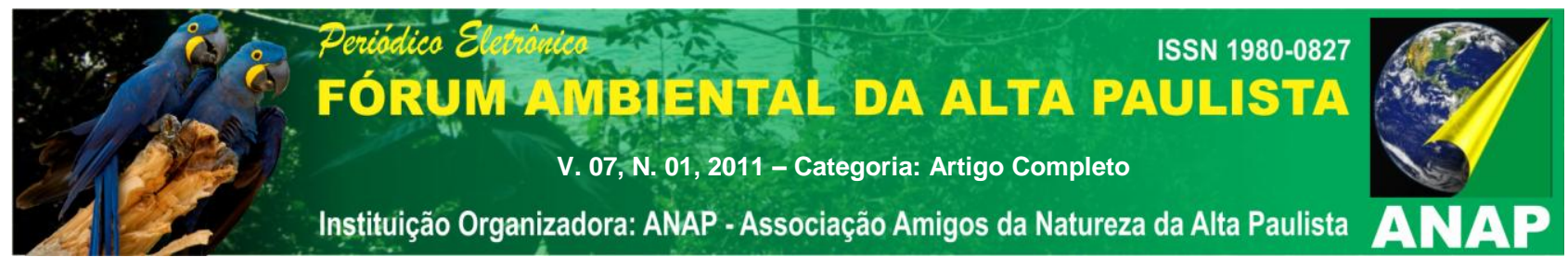

nacional, de 8,4\% em 2000 para 9,6\% em 2009. A região Norte vem em quinto com uma participação que evolui de $3,8 \%$ para $4,5 \%$ no período.

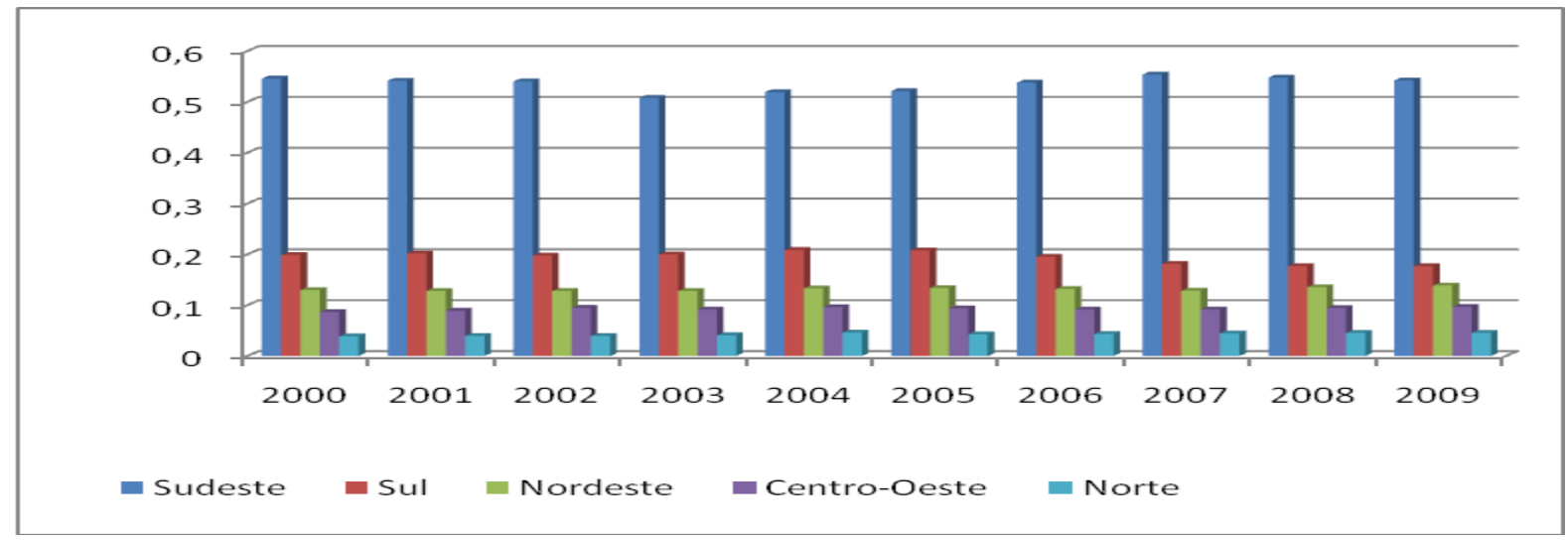

Figura 2: Participação no consumo das regiões Sudeste, Nordeste, Sul, Sudeste e Norte no consumo de gasolina C e etanol nacional, de 2000 até 2009.

Fonte: ANP (2010)

$\mathrm{Na}$ região Sudeste, analisando-se os principais estados consumidores da região Sudeste, percebe-se que o Estado de São Paulo tem grande participação no consumo de combustíveis na região, detendo participação de $67,4 \%$ no ano de 2009 , em seguida vem Minas Gerais com participação de 18,5\%, Rio de Janeiro em terceiro com aproximadamente $11 \%$ e em quarto encontra-se o Espírito Santo com participação de apenas $3 \%$.

Devido à pequena participação no consumo de combustíveis do Espírito Santo na região, concentra-se a análise na evolução da demanda por tipo de combustíveis nos três maiores estados consumidores da região. Na região Sudeste, o estado de São Paulo foi o grande responsável pela elevação do consumo de etanol no período analisado, ver figura 3. No ano de 2009, o consumo de etanol suplantou o consumo de gasolina C, observando-se $56,2 \%$ do consumo de etanol contra $43,7 \%$ do consumo de gasolina C. Nos demais estados representativos da demanda da região, este fenômeno não ocorre. No estado de Minas Gerais, o consumo de gasolina representou 71,4\% em 2009, destacando-se a perda de percentual de consumo, pois em 2000 representava 80,8 \% do consumo. O estado o Rio de Janeiro, o consumo de gasolina representou 65,2\% em 


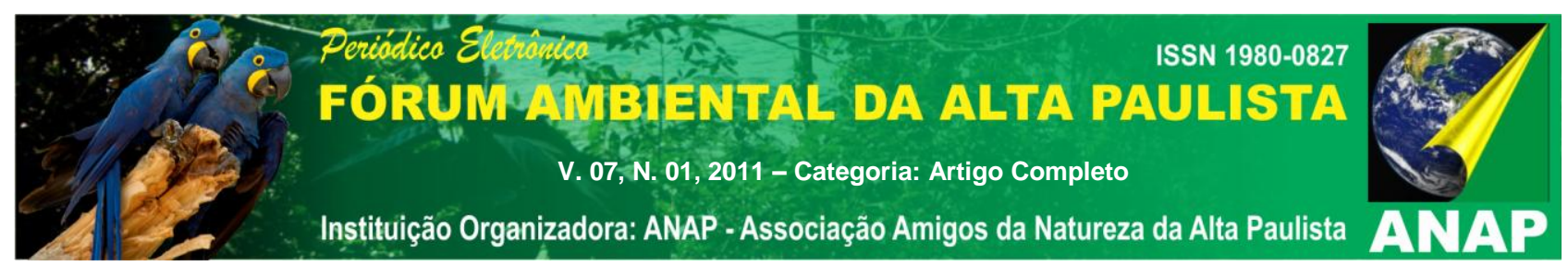

2009, ocorrendo também perda no percentual consumido, pois representava demanda de $88 \%$ em 2000.

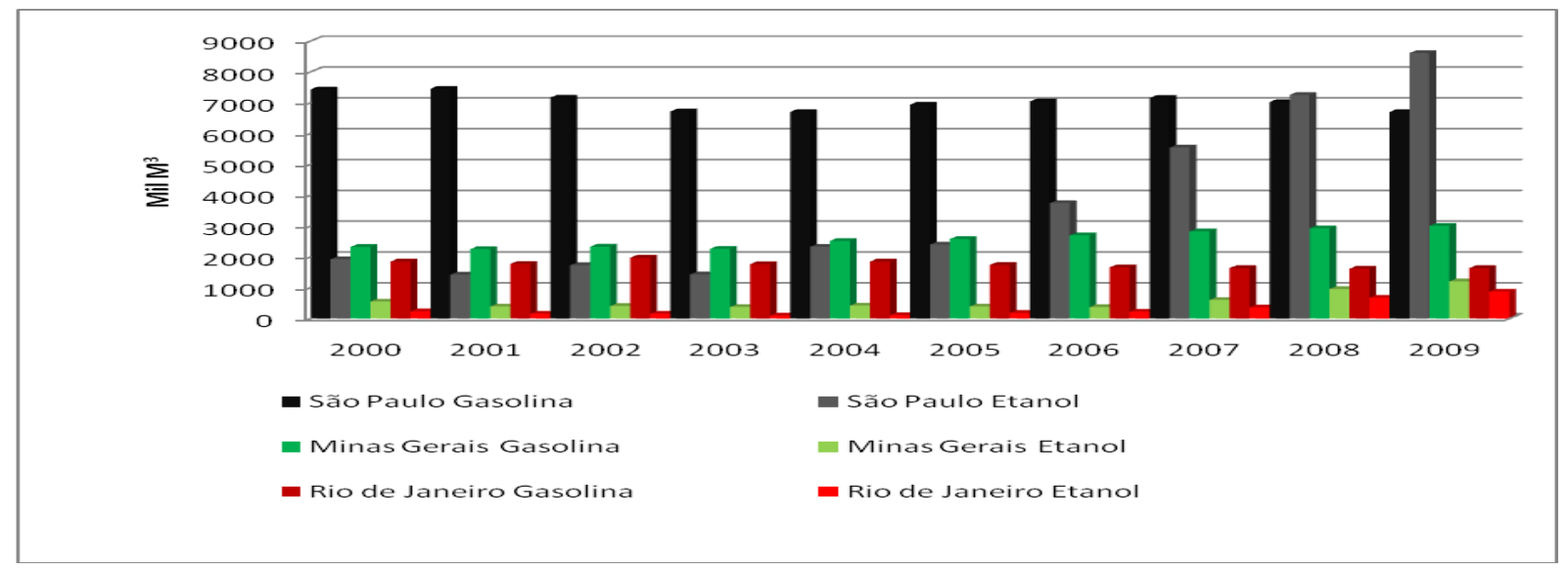

Figura 3: Consumo de gasolina e etanol nos estados de São Paulo, Minas Gerais e Rio de Janeiro entre 2000 e 2009, unidade de medida: Mil $\mathrm{M}^{3}$

Fonte: ANP (2010)

Na região Sul, analisando-se a demanda por combustível nos estados do Sul, observa-se que o estado do Paraná foi o grande responsável pelo crescimento no consumo de etanol, ver figura 10. Também ocorreu elevação, mas em menor magnitude, nos estados de Santa Catarina e Rio Grande do Sul. Em termos de taxa de crescimento do consumo de etanol, o estado de Santa Catarina apresentou elevação de $180 \%$ na demanda por etanol, o Paraná apresentou crescimento de $160 \%$ e o Rio Grande do Sul de $134 \%$.

$\mathrm{Na}$ região Nordeste, realizando-se uma análise para os quatro maiores demandantes de combustível (Bahia, Pernambuco, Ceará e Maranhão) do Nordeste que respondem por aproximadamente $70 \%$ do consumo gasolina $\mathrm{C}$ e etanol, observa-se que a Bahia foi o maior demandante de gasolina C e etanol, ver figura 12, seguido por Pernambuco, Ceará e Maranhão.

Em todos os estados analisados o consumo de gasolina responde majoritariamente pelo consumo de combustíveis, variando de 65,7\% em Pernambuco até 79,2\% no Ceará no ano de 2009. No entanto, em todos os estados vem ocorrendo elevação mais 


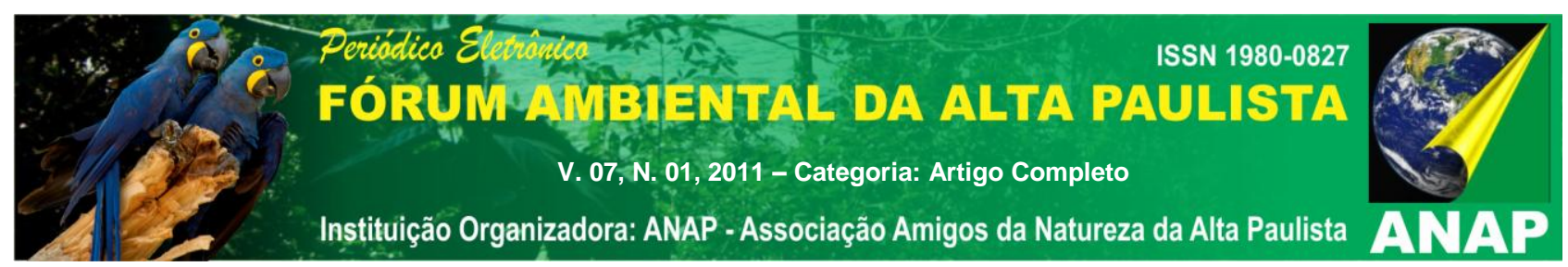

acentuada no consumo de etanol em relação ao consumo de gasolina, principalmente a partir de 2003 com a venda de veículos bicombustíveis. O Maranhão apresentou maior elevação na demanda por etanol em aproximadamente $752 \%$, seguido pela Bahia em 433\% e Pernambuco com 366\%, ver figura 4.

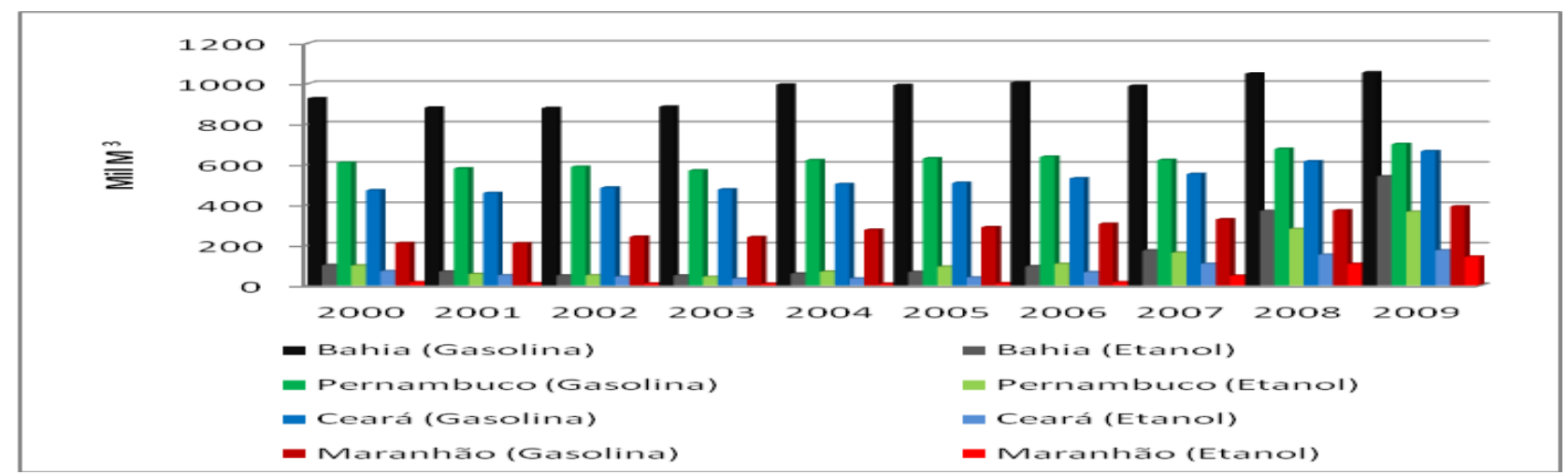

Figura 4: Consumo de gasolina e etanol na Bahia, Pernambuco, Ceará e Maranhão entre 2000 e 2009, unidade de medida: Mil $\mathrm{M}^{3}$

Fonte: ANP (2010)

$\mathrm{Na}$ região Centro-Oeste, Goiás destaca-se como o maior consumidor de combustíveis na região com 42,5\% da demanda regional, foi quem mais contribuiu para a elevação na demanda de etanol, ver figura 5. No entanto, Mato Grosso apresentou maior taxa de elevação, de aproximadamente 543\%, na demanda por etanol entre 2009 e 2000. Goiás apresentou elevação de aproximadamente 306\% e Mato Grosso do Sul ocorreu incremento de aproximadamente $200 \%$. 

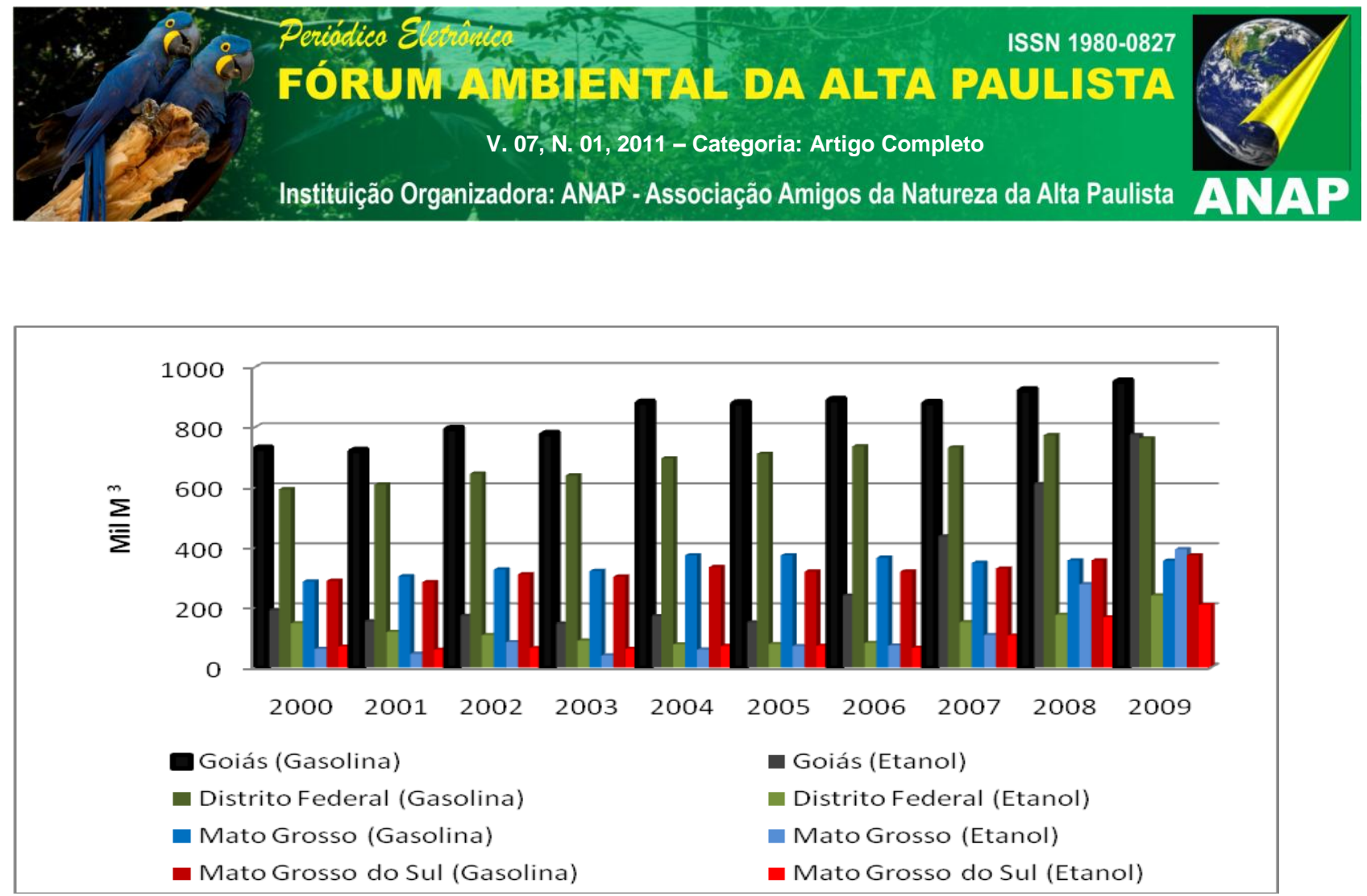

Figura 5: Consumo de gasolina e etanol em Goiás, Distrito Federal, Mato Grosso e Mato Grosso do Sul entre 2000 e 2009. Unidade de medida: Mil M ${ }^{3}$

Fonte: ANP (2010)

Analisando-se as quatro regiões brasileiras demandantes e produtoras de etanol e os principais estados consumidores de cada região, percebe-se características diferenciadas no consumo de combustíveis líquidos e na taxa de crescimento na demanda pelos combustíveis. O estado de São Paulo foi o estado quem mais contribuiu para a elevação da demanda por etanol na região Sudeste e no Brasil. Estados como Paraná, Goiás e Mato Grosso também apresentaram grande crecimento na demanda por etanol. Em todos estes estados, o preço do etanol se mostrou amplamente favorável em relação a gasolina no período.

Para se explicar a maior demanda por etanol em alguns estados deve-se considerar dois fatores explicativos, a proximidade entre a produção e a demanda reduzindo os custos de transporte e incidência de ICMS sobre a gasolina e o etanol hidratado. Conforme dados da UNICA (2011), São Paulo, Paraná, Goiás, Mato Grosso do Sul e Mato Grosso responderam por aproximadamente $92 \%$ da produçcão de etanol na safra 2008/09. Estes estados respondem por 74,2\% da demanda nacional de etanol hidratado no ano de 2009. 


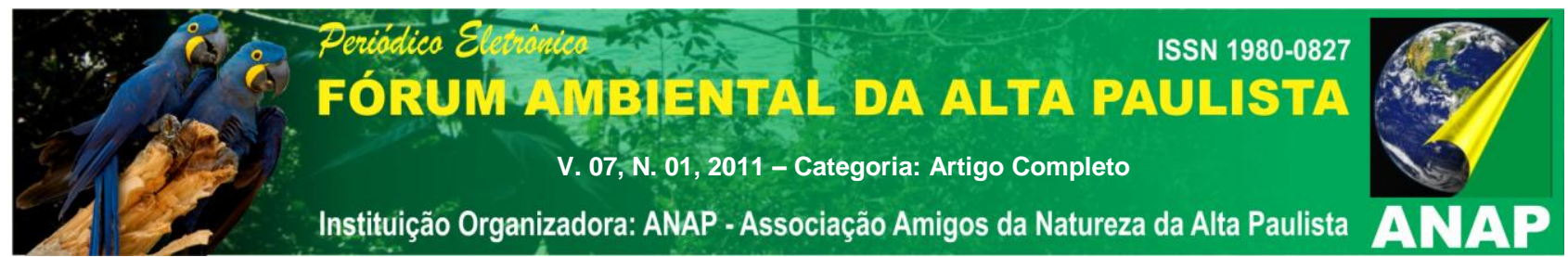

Alguns estados adotam incidência de ICMS diferenciada entre gasolina e etanol hidratado, ver tabela 1,. Destes estados, três são também grandes produtores (São Paulo, Paraná e Goiás). Os estados com redução de ICMS responderam por aproximadamente $80 \%$ da demanda por etanol hidratado no ano de 2009. Estes estados responderam por aproximadamente $72,8 \%$ da demanda por etanol hidratado no ano de 2009.

Tabela 1: Incidência de ICMS sobre gasolina C e etanol hidratado nos estados de São Paulo, Rio de Janeiro, Paraná, Goiás e Bahia vigentes em maio de 2009.

\begin{tabular}{|l|l|l|}
\hline Estados da Federação & ICMS sobre a gasolina C & $\begin{array}{l}\text { ICMS sobre o etanol } \\
\text { hidratado }\end{array}$ \\
\hline São Paulo & 25 & 12 \\
\hline Rio de Janeiro & 31 & 24 \\
\hline Paraná & 28 & 18 \\
\hline Goiás & 26 & 20 \\
\hline Bahia & 27 & 19 \\
\hline
\end{tabular}

FONTE: CONAB (2009)

\section{CONCLUSÃO}

Neste artigo, realizou-se uma análise exploratória e comparativa sobre a demanda por etanol em relação a gasolina e ao GNV no mercado automotivo brasileiro entre 2000 e 2009. Observou-se crescimento da demanda por combustíveis automotivos em geral no mercado brasileiro, passando de aproximadamente 27,2 mil $\mathrm{M}^{3}$ em 2000 para aproximadamente 41, 9 mil $\mathrm{M}^{3}$ em 2009. Registrando-se crescimento de aproximadamente $53,8 \%$. A gasolina tipo C é o tipo de combustível mais demandado no mercado de combustíveis, respondendo por $58 \%$ da demanda em 2009. No etanto, ocorreu declínio na participação da demanda do combustível entre 2000 e 2009, pois em 2000 a gasolina respondia por $82 \%$ da demanda de combustíveis. 


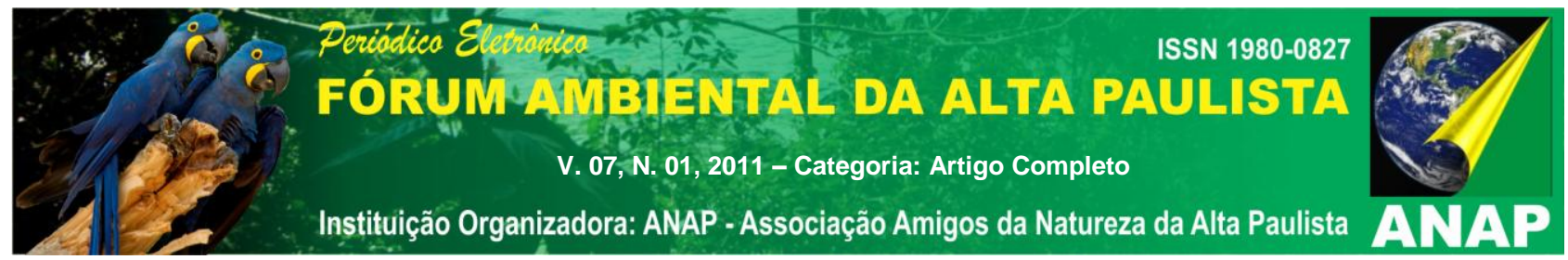

O etanol foi o combustível automotivo com maior taxa de crescimento da demanda nacional no período. Passando de 4,6 mil M $\mathrm{M}^{3}$ em 2000 para aproximadamente $16,5 \mathrm{mil} \mathrm{M}^{3}$ em 2009, observando-se crescimento de aproximadamente $268 \%$. A taxa de participação do etanol passou de 17\% em 2000 para 38\% em 2009. No período, os preços do etanol se mostraram mais competitivos em relação a gasolina, justificando assim o crecimento da demanda por este combustível.

Constatou-se concentração regional e estadual na demanda por combustíveis no Brasil. A região Sudeste respondeu por $54,2 \%$ no consumo de combustíveis líquidos no mercado nacional e o estado de São Paulo respondeu por 67,4\% da demanda por combustíveis no Sudeste. Desta forma, os acontecimentos no mercado de combustível no Sudeste e em particular em São Paulo têm forte impacto no mercado nacional de combustíveis.

A região Sudeste, com grande influência do estado de São Paulo, registrou decrescimento na demanda de gasolina e forte crescimento na demanda de etanol. No estado de São Paulo, a demanda por etanol superou a demanda por gasolina em 2009, observando-se $56,2 \%$ do consumo de etanol contra $43,7 \%$ do consumo de gasolina. As vendas de etanol no estado passaram de 1,9 $\mathrm{mil} \mathrm{M}^{3}$ em 2000 para aproximadamente 8,6 mil M³ em 2009.

$\mathrm{Na}$ região Sul, segunda região com maior demanda de combustíveis automotivos no Brasil, respondendo por $17,6 \%$ da demanda por combustíveis no mercado nacional em 2009, constatou-se majoritariamente consumo de gasolina em relação ao etanol, respondendo por aproximadamente $72 \%$ do consumo de combustíveis no ano. No entanto, ocorreu elevação no consumo por etanol na magnitude de 154\% entre 2000 e 2009. Sendo o estado do Paraná o grande responsável pelo crescimento da demanda por etanol na região.

A região Nordeste, terceira região demandante, também se caracteriza por consumo majoritário de gasolina em relação ao etanol. No ano de 2009, a gasolina respondeu por $72 \%$ do consumo de combustíveis. No entanto, ocorreu crescimento na demanda de etanol no montante de $266 \%$ no período. A Bahia, maior estado demandante 


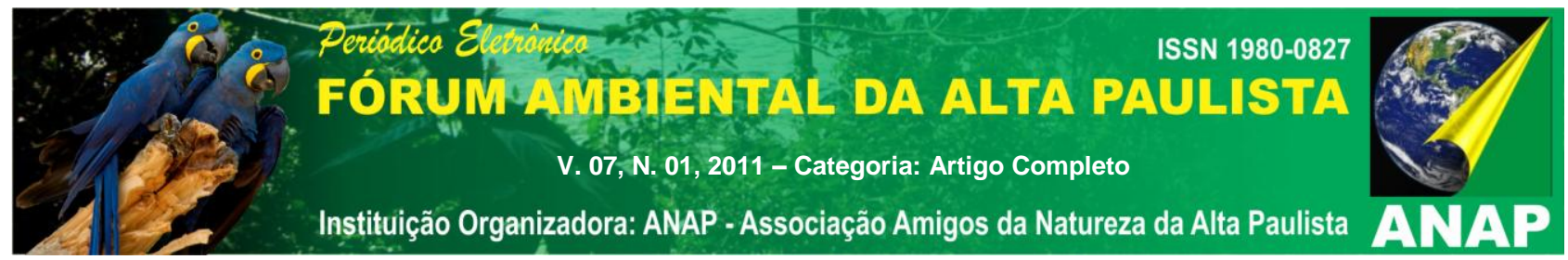

de combustíveis na região, respondendo por $28 \%$ do consumo na região, foi o estado em que mais se observou elevação na demanda por etanol em relação a gasolina.

No Centro-Oeste, observa-se grande incremento na demanda por etanol em relação a gasolina. Os estados de Goiás e Mato Grosso apresentaram grande crescimento da demanda por etanol em relação a gasolina. No estado do Mato Grosso, a demanda por etanol chegou a superar a demanda por gasolina em 2009.

Finalizando, a pesquisa exploratória e comparativa realizada neste artigo serve como base para a realização de novas pesquisas procurando analisar o motivo pelos quais existe diferenças estaduais no consumo de combustíveis automotivos e nos níveis de preços relativos entre etanol e gasolina. Os estados que apresentaram maior taxa de crescimento da demanda por etanol também são grandes produtores do produto e/ou possuem políticas de alíquotas diferenciadas de ICMS para o etanol e a gasolina. Fazendo-se a necessidade de analisar se as vantagens de preços do etanol em relação a gasolina decorrem da vantagem logística da proximidade do consumidor em relação ao produtor, ou a vantagem decorre da incidência de impostos estaduais favoráveis ao etanol em relação a gasolina.

Necessitando-se também realizar uma análise comparativa dos custos de produção e distribuição do etanol e da gasolina em em um nível nacional, regional e estadual, com o objetivo de se avaliar a evolução das vantagens comparativas de uma alternativa de combustível em relação a outra.

\section{REFERÊNCIA BIBLIOGRÁFICA}

ANP. Anuário Estatístico Brasileiro do Petróleo, Gás Natural e Bicombustíveis de 2010. Disponível em: http://www.anp.gov.br/. Acesso em: 25 jan. 2011.

CARROANTIGO. História do carro brasileiro. Disponível em: http://www.carroantigo.com/portugues/conteudo/curio hist carro brasileiro.htm Acesso em: 2 fev. 2011

CLICKMACAÉ. As crises do Petróleo. Disponível em: http://www.clickmacae.com.br/?sec=109\&pag=pagina\&cod=205. Acesso em 2 fev. 2011. 
CONAB. Os fundamentos da crise do setor sucroalcooleiro no Brasil. Disponível em: http://www.conab.gov.br/conabweb/download/nupin/estudo crise cana.pdf. Acesso em 2 ago. 2011.

EMPRESA DE PESQUISA ENERGÉTICA. Balanço Energético Nacional 2010. Disponível em https://ben.epe.gov.br/downloads/Relatorio Final BEN 2010.pdf. Acesso em: 30 jan. 2011.

FIGUEIRA, S.R. Os programas de álcool como combustível nos EUA, no Japão e na União Européia e as possibilidades de exportação do Brasil. 2005. 182 p. Tese (Doutorado em Ciências, Área de Concentração: Economia Aplicada) - Escola Superior de Agricultura "Luiz de Queiroiz", Universidade de São Paulo, Piracicaba, 2005.

GASNET. O uso do GN em veículos GNV. Disponível em: http://www.gasnet.com.br/novo gnv/entendendo gnv.asp. Acesso em: 3 fev. 2011. GIL, A.C. Como elaborar projetos de pesquisa. São Paulo. Editora Atlas S.A. 2008 IPEADATA. Produção de gasolina no Brasil. Disponível em: http://www.ipeadata.gov.br/ipeaweb.dll/ipeadata?SessionID=2123039882\&Tick=12972754 98796\&VAR FUNCAO=Ser Temas\%28120\%29\&Mod=M. Acesso em: 30 jan. $2011 \mathrm{a}$.

SCHNEIDER, S.SCHMITT, C.J. O uso do método comparativo nas ciências socias. Cadernos de Sociologia, Porto Alegre, v.9, p. 49-87, 1998.

UNICA. Vendas de carros movidos a gasolina, etanol e bicombustíveis . Disponível em: http://www.unica.com.br/. Acesso em: 2 fev 2011.

UNICA. Produção de etanol no Brasil. São Paulo. Disponível em: www.unica.com.br/ Acesso em : 2 ago. 2011.

WILKIPEDIA. Gasolina. Disponível em http://pt.wikipedia.org/wiki/Gasolina. Acesso em: 2 fev. 2011a.

WILKIPEDIA. Automóvel . Disponível em http://pt.wikipedia.org/wiki/Autom\%C3\%B3vel. Acesso em: 3 fev. 2011b.

WILKIPEDIA. Gás natural. Disponível em: http://pt.wikipedia.org/wiki/G\%C3\%A1s natural. Acesso eem: 5 fev. 2011c. 


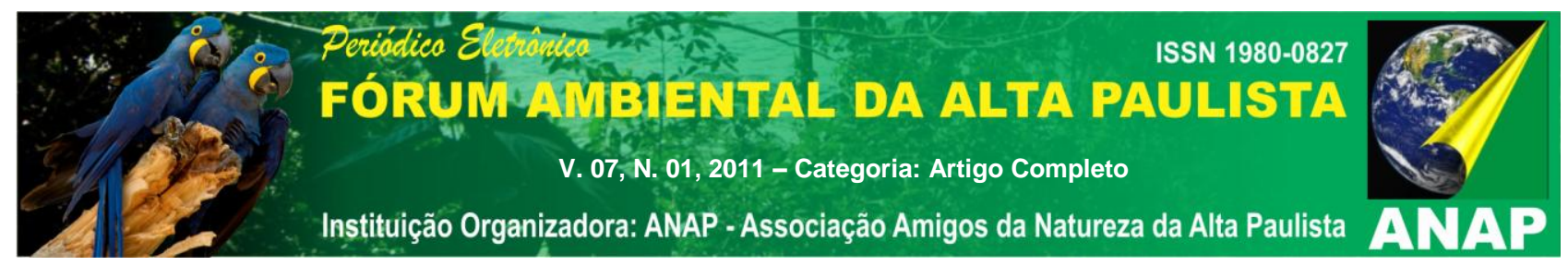

